\title{
Frail Older Adults with Presymptomatic SARS-CoV-2 Infection: Clinical Course and Prognosis
}

\author{
Yochai Levya,b Adi Turjeman $^{b, c}$ Lisa Coopera, ${ }^{a} \quad$ Nadya Kagansky ${ }^{b} d$ \\ Tatiana Nagulevich ${ }^{\mathrm{e}}$ Tamari Snir ${ }^{\mathrm{e}}$ Avital Hershkovitz ${ }^{\mathrm{b}, \mathrm{f}}$ Avraham Weiss $^{\mathrm{a}, \mathrm{b}}$ \\ Yichayaou Beloosesky ${ }^{a, b}$ Yaara Leibovici Weissman ${ }^{b, g}$ \\ aDepartment of Acute Geriatrics, Rabin Medical Center, Beilinson Campus, Petah Tikva, Israel; bSackler Faculty of \\ Medicine, Tel Aviv University, Tel Aviv, Israel; 'Research Authority, Rabin Medical Center, Petah Tikva, Israel; \\ 'Shmuel Harofeh Medical Center, Be'er Yaakov, Israel; ' Geriatric Center Golden-Care, Ness Ziona, Israel; 'Department \\ of Geriatrics, Beit Rivka Geriatric Rehabilitation Center, Petah Tikva, Israel; IInternal Medicine Department E, \\ Rabin Medical Center, Beilinson Campus, Petah Tikva, Israel
}

\section{Keywords}

Coronavirus disease $\cdot$ Older adults $\cdot$ Long-term care .

Frailty · Vitamin D

\begin{abstract}
Background/Aims: The novel coronavirus SARS-CoV-2 has caused a pandemic threatening millions of people worldwide. This study aimed to describe clinical characteristics, outcomes, and risk factors of SARS-CoV-2-positive, asymptomatic, frail older adults. Methods: A retrospective cohort study was conducted in 6 designated COVID-19 units, in skilled nursing homes. Subjects were severely frail older adults, positive for SARS-CoV-2, and asymptomatic at the time of their admission in these units. Residents' characteristics and symptoms were obtained via electronic medical records. The primary outcome was a composite of death or hospitalization by day 40 . We looked at time to the primary outcome and used Cox regression for a multivariate analysis. Results: During March-November 2020, 849 residents met inclusion criteria. Median age was 84 years. Most were completely dependent for basic activities of daily living and
\end{abstract}

showed cognitive impairment. Six hundred forty-one (75.5\%) residents were discharged after considered cured from COVID-19, 125 (14.7\%) were hospitalized, and 82 (9.7\%) died in the facilities. In survival analysis, 35\% reached the primary outcome of death or hospitalization by day 40 . Age (hazard ratio $[\mathrm{HR}] 1.23$; $95 \%$ confidence interval $[\mathrm{Cl}] 1.1-1.4)$, male gender (HR 1.41; 95\% Cl: 1.1-1.88), and COPD (HR 1.8; 95\% Cl: 1.23-2.67) were significant risk factors. Conclusions: In this large cohort, we report care and prognosis of asymptomatic older adults with major functional or cognitive impairments during the COVID-19 pandemic. Most presymptomatic patients do not develop severe infection, and age stays a predominant risk factor, even in the frailest older adults.

(c) 2022 S. Karger AG, Basel

\section{Introduction}

The novel coronavirus SARS-CoV-2 has caused a pandemic threatening millions of people worldwide. The clinical presentation of coronavirus disease (COVID-19) ranges from asymptomatic or mild disease to severe 
Fig. 1. Study flowchart.

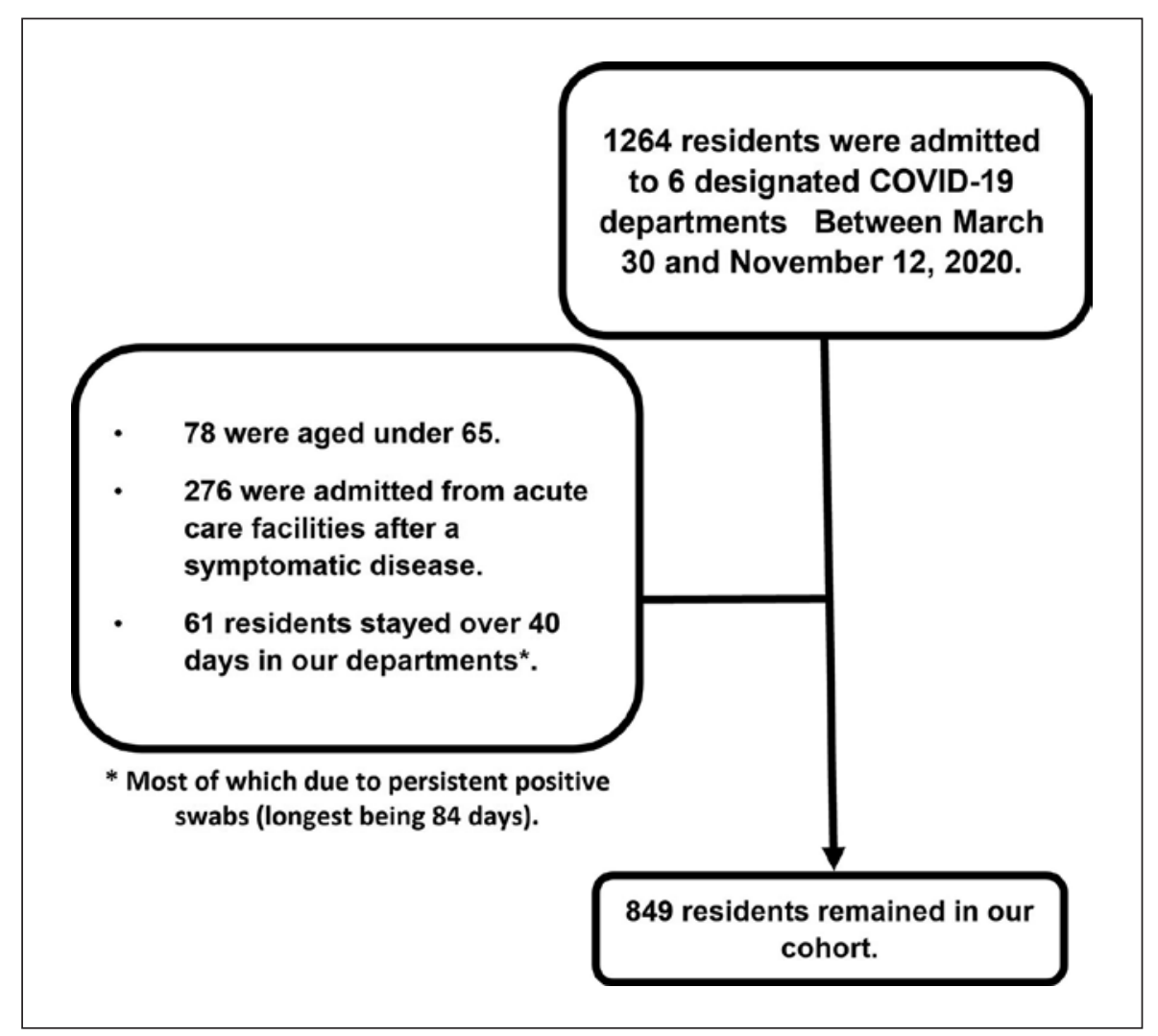

pneumonia, respiratory failure, and death [1]. Old age and frailty are among the main risk factors for a severe disease $[2,3]$. Nursing home residents are at extreme risk of outbreaks due to crowded living arrangements and high exposure rates to staff and outside visitors. These factors, along with frailty, multimorbidity, and older age, lead to grim outcomes. Deaths occurring at nursing homes account for approximately $25 \%$ of reported deaths in the USA $[4,5]$. Several recommendations for preventing and managing SARS-CoV-2 outbreaks in nursing homes were proposed in the USA. These include testing and isolating suspected residents, routine resident screening, isolating SARS-CoV-2-positive patients in designated wards within the nursing home, or transferring them to an acute care unit [6].

Reports on outcomes of pre- and asymptomatic, SARS-CoV-2-positive nursing home residents are still lacking and are needed to optimize care for this at-risk population during the pandemic. In Israel, a policy of routine screening for SARS-CoV-2 among nursing home residents was implemented early during the pandemic. Most dependent, asymptomatic residents positive for SARS-CoV-2 were isolated and managed in designated
COVID-19 units, of skilled nursing homes [7]. This policy was meant to ensure better infection control while allowing personal contact between residents who are positive for SARS-CoV-2, thus minimizing the potential harms of social isolation. Furthermore, the residents received treatment from experienced staff members, accustomed to working with personal protective equipment (PPE). In this study, we present the outcomes of frail older adults, isolated in such designated units. Our hypothesis was that this frail population would suffer worse outcomes. Furthermore, we stipulated that due to their very low performance status and extreme frailty, age would be a weaker risk factor for COVID-19 adverse events, in comparison with its effect in the general population $[8,9]$.

\section{Methods}

Study Design and Participants

This was a retrospective, observational cohort study of older adults, admitted to designated COVID-19 units, in a chain of skilled nursing homes in Israel, between March 30 and November 12,2020 . This timeframe was that of the original SARS-CoV-2 virus and pre-dated the emergence of variants defined as Variant of 
Interest, or Variant of Concern, etc. The COVID-19 units were created in the skilled nursing homes, using isolated areas with designated multidisciplinary staff trained to use complete PPE.

Participants were found positive for SARS-CoV-2 and were asymptomatic at time of admission. It is important to mention that the data gathered and presented here were collected before the era of COVID-19 vaccines, which were first administered in Israel in December 2020. Thus, all participants were unvaccinated.

All residents needed continuous supervision and care due to major functional and/or cognitive impairments, indicating severe frailty according to the Clinical Frailty Scale [10]. Residents received care for their basic activities of daily living needs. If they developed COVID-19-related symptoms (see definitions below), they received medical care inside the units. Residents who developed severe disease were either transferred to a nearby hospital or remained in the facilities and received treatment there, according to goals of care stated by the resident or primary caregiver upon admission. After recovery from COVID-19, residents returned to their prior accommodations.

\section{Inclusion and Exclusion Criteria}

We included residents admitted to the designated COVID-19 units, who were asymptomatic (free of COVID-19 symptoms) upon admission. All residents needed continuous supervision and care due to major functional and/or cognitive impairments. We excluded residents who were admitted to our facilities from acute care facilities, those aged under 65 years, and those who stayed for more than 40 days in the facilities (to prevent introducing biases which might have led to a very long institutional stay).

\section{Disease and Recovery Definitions}

SARS-CoV-2 tests were performed using real-time reversetranscription polymerase chain reaction analysis of throat swabs. COVID-19 symptoms were defined as fever over $38^{\circ} \mathrm{C}$, new respiratory complaints, or a new decrease in pulse oxygen saturation $\left(\mathrm{SpO}_{2}\right)$. COVID-19 symptomatic residents were treated according to Israeli treatment protocols. Treatment protocols during the described time period were adjusted to match emerging data concerning treatment effects. Starting June 2020, residents who developed symptoms including $\mathrm{SpO}_{2}<92 \%$ were given dexamethasone in concordance with the published literature [11]. Intravenous fluids were administered according to medical clinical judgment.

Severe disease requiring hospitalization was defined as respiratory distress or $\mathrm{SpO}_{2}$ under $92 \%$, unresponsive to low flow oxygen (given with a nasal cannula, in a rate up to $5 / \mathrm{L} / \mathrm{min}$ ), significant change in level of conscience, or hemodynamically unstable patients. At the beginning of the pandemic (starting March 2020 in Israel), recovery was defined by two negative swabs, at least 10 days after the COVID-19 diagnosis, and the patient being free from symptoms for at least 3 days. On October 2, 2020, guidelines were amended so that a negative polymerase chain reaction test was no longer mandatory, and residents were also eligible for discharge after 20 days, providing they were symptom free during the last 3 days.

\section{Data Collection}

Data were retrieved from electronic medical records and included demographics, such as age and gender of residents, comorbidities, performance status, and chronic medications. For all participants, the Charlson Comorbidity Index [12] and the Katz Index of Independence for Activities of Daily Living [13] were calculated.
Table 1. Residents' characteristics

$\begin{array}{ll}\text { All included residents } & 849(100) \\ \text { Age (median, IQR)* } & 84(78-90) \\ \text { Gender, male } & 292(34.4) \\ \text { Arrived from } & \\ \quad \text { Home } & 23(2.7) \\ \text { Long-term care facility } & 765(90.1) \\ \text { Rehabilitation } & 61(7.2) \\ \text { KATZ Index (median, 25\%-75\%) } & 1.09(0-1) \\ \text { Comorbidities } & \\ \text { Charlson Comorbidity Index** (median, 25\%-75\%) } & 6(5-7) \\ \text { Dementia } & 700(82.4) \\ \text { Pressure ulcer } & 102(12.0) \\ \text { Diabetes mellitus } & 318(37.5) \\ \text { Hypertension } & 610(71.8) \\ \text { COPD } & 97(11.4) \\ \text { Cerebrovascular disease } & 217(25.6) \\ \text { Ischemic heart disease } & 188(22.1) \\ \text { Congestive heart failure } & 115(13.5) \\ \text { PVD } & 164(19.3) \\ \text { Obesity } & 67(7.9) \\ \text { Hyperlipidemia } & 348(41.0) \\ \text { Malignancy } & 114(13.4) \\ \text { Psychiatric disorder } & 63(7.4) \\ \text { Parkinson's disease } & 90(10.6) \\ \text { Atrial fibrillation } & 183(21.6) \\ \text { Chronic medications } & \\ \text { Vitamin D } & 208(24.5) \\ \text { Anticonvulsants } & 58(6.8) \\ \text { Benzodiazepines } & 415(48.9) \\ \text { Beta-blockers } & 309(36.4) \\ \text { Narcotics } & 62(7.3) \\ \text { ACE inhibitors } & 169(19.9) \\ \text { Diuretics } & 216(25.4) \\ \text { Aspirin } & 159(18.7) \\ \text { Prophylactic anticoagulants } & 65(7.7) \\ & \end{array}$

Data are presented as numbers (\%), unless otherwise indicated. $\mathrm{IQR}$, interquartile range; $\mathrm{Cl}$, confidence interval; $\mathrm{COPD}$, chronic obstructive pulmonary disease; PVD, peripheral vascular disease; $A C E$, angiotensin-converting enzyme. ${ }^{*}$ Age - per 1-year increment. ** Charlson Comorbidity Index - per one-grade increment.

All participants had daily recording of vital signs including temperature, oxygen saturation level $\left(\mathrm{SpO}_{2}\right)$, and blood pressure measurements. Our primary outcome was a composite outcome of mortality and hospitalization in residents staying up to 40 days in the designated units.

\section{Statistical Analysis}

Continuous variables are expressed as mean \pm standard deviation for normally distributed variables and as median and interquartile range (IQR, 25th-75th percentiles) for others. Categorical data are summarized as frequencies (percentages).

The association between independent variables and the primary outcome was assessed using Kaplan-Meier survival analysis and tested for statistical significance using the log-rank test. We en- 


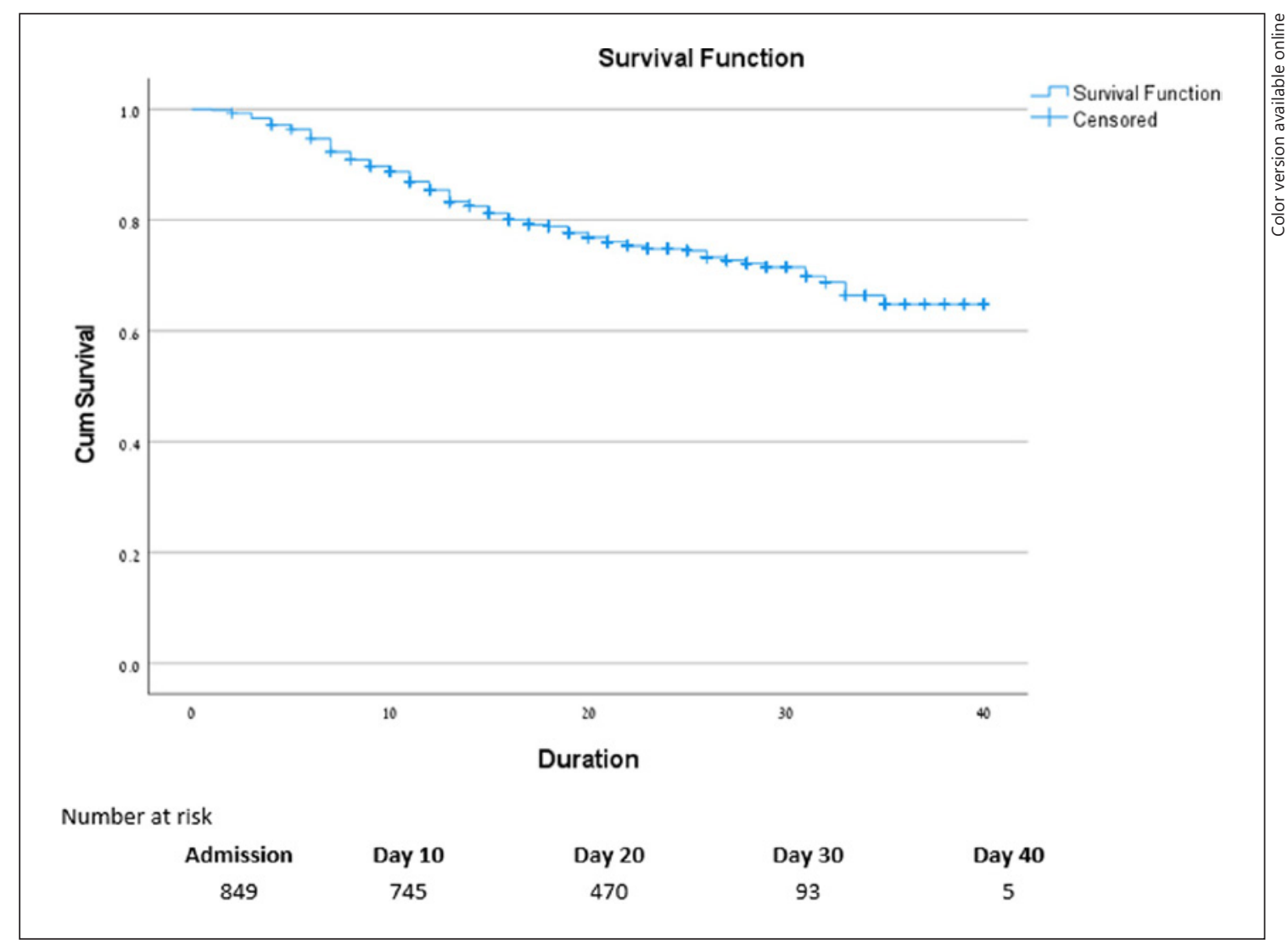

Fig. 2. Kaplan-Meier curve for severe symptomatic disease-free survival. Cum survival, cumulative survival; duration, duration of follow-up (days).

tered variables with a $p$ value $\leq 0.15$ and clinical plausibility into a multivariate analysis using the Cox proportional hazard model to identify independent risk factors for 40-day hospitalization or mortality. Hazard ratio (HR) and 95\% confidence interval (CI) were calculated. Analyses were conducted using IBM SPSS Statistics, version 27 .

\section{Results}

Between March 30 and November 12, 2020, a total of 1,264 residents were admitted to 6 designated COVID-19 units, which opened gradually during the study period. After implementing exclusion criteria, 849 residents remained in our cohort (Fig. 1). Resident's baseline characteristics are described in Table 1 . The median age was 84 years (IQR 78-90), and 282 (34.4\%) residents were male. Most residents were admitted from long-term care facilities and were severely dependent on caregivers for most basic activities of daily living, with a mean KATZ Index of 1.1 (IQR 0-1). Seven hundred residents (82\%) suffered some degree of cognitive impairment. Most residents were admitted from long-term care facilities, and only 33 (2.6\%) were admitted from home with a caregiver, as they were unable to complete the isolation requirements there.

A total of 641 (75.5\%) residents were discharged from our facilities after considered cured from COVID-19, 125 (14.7\%) were hospitalized, and 82 (9.7\%) died in our facilities. Survival analysis showed that $35 \%$ of residents reached the composite outcome of death or hospitalization by day 40 (Fig. 2). Fever of at least $38^{\circ} \mathrm{C}$ was measured in $287(33.8 \%)$ residents during the observation period, and $47 \%$ of them were hospitalized or died. Three hundred and five (36\%) residents had $\mathrm{SpO}_{2}<92 \%$ during the observation period, and $34 \%$ of them reached the primary outcome. Fever $>38^{\circ} \mathrm{C}$ and/or $\mathrm{SpO}_{2}<92 \%$ was found in 443 residents (52\%). A total of 485 residents (57\%) developed symptoms during their stay.

In a bivariate risk analysis (Table 2), age was the predominant risk factor for time to the composite outcome of death or hospitalization. The Charlson Comorbidity Index and chronicobstructive pulmonary disease (COPD) were significant risk factors while chronic treatment with 
Table 2. Univariate analysis of risk factors for severe symptomatic disease, Kaplan-Meier survival analysis (mean, 95\% Cl)

\begin{tabular}{|c|c|c|c|c|c|}
\hline Variable & Values & Cases, $N$ & $\begin{array}{l}\text { Events, } \\
N\end{array}$ & $\begin{array}{l}\text { Mean survival days } \\
(95 \% \mathrm{Cl})\end{array}$ & $\begin{array}{l}p \text { value } \\
\text { (log-rank) }\end{array}$ \\
\hline Age & $\begin{array}{l}<78 \text { years } \\
78-84 \text { years } \\
85-90 \text { years } \\
>90 \text { years }\end{array}$ & $\begin{array}{l}209 \\
218 \\
217 \\
205\end{array}$ & $\begin{array}{l}40 \\
45 \\
54 \\
68\end{array}$ & $\begin{array}{l}33.3(31.6-34.9) \\
33.0(31.2-34.8) \\
32.1(30.2-33.9) \\
29.0(26.9-31.2)\end{array}$ & 0.010 \\
\hline Gender & $\begin{array}{l}\text { Male } \\
\text { Female }\end{array}$ & $\begin{array}{l}292 \\
557\end{array}$ & $\begin{array}{l}81 \\
126\end{array}$ & $\begin{array}{l}30.9(29.2-32.6) \\
32.5(0.1 .3-32.9)\end{array}$ & 0.126 \\
\hline Pressure ulcer & $\begin{array}{l}\text { No } \\
\text { Yes }\end{array}$ & $\begin{array}{l}746 \\
102\end{array}$ & $\begin{array}{l}181 \\
26\end{array}$ & $\begin{array}{l}32.0(31.0-33.0) \\
30.8(28.0-33.5)\end{array}$ & 0.533 \\
\hline Charlson Comorbidity Index & $\begin{array}{l}\leq 5 \\
>5\end{array}$ & $\begin{array}{l}311 \\
538\end{array}$ & $\begin{array}{l}61 \\
146\end{array}$ & $\begin{array}{l}33.8(32.4-35.2) \\
31.0(29.7-32.2)\end{array}$ & 0.015 \\
\hline KATZ Index & $\begin{array}{l}0,1 \\
2-6\end{array}$ & $\begin{array}{l}671 \\
174\end{array}$ & $\begin{array}{l}164 \\
43\end{array}$ & $\begin{array}{l}31.9(30.8-33.0) \\
32.1(30.0-34.1)\end{array}$ & 0.737 \\
\hline Admission month & $\begin{array}{l}\text { Apr-Jul } \\
\text { Aug-Nov }\end{array}$ & $\begin{array}{l}260 \\
589\end{array}$ & $\begin{array}{l}97 \\
110\end{array}$ & $\begin{array}{l}28.4(26.6-30.2) \\
33.9(32.9-35.0)\end{array}$ & $<0.001$ \\
\hline Comorbidities & & & & & \\
\hline Dementia & $\begin{array}{l}\text { No } \\
\text { Yes }\end{array}$ & $\begin{array}{l}140 \\
709\end{array}$ & $\begin{array}{l}35 \\
172\end{array}$ & $\begin{array}{l}30.7(28.6-32.8) \\
31.9(30.8-33.0)\end{array}$ & 0.755 \\
\hline Diabetes mellitus & $\begin{array}{l}\text { No } \\
\text { Yes }\end{array}$ & $\begin{array}{l}531 \\
318\end{array}$ & $\begin{array}{l}123 \\
84\end{array}$ & $\begin{array}{l}32.2(31.0-33.4) \\
31.4(29.8-33.0)\end{array}$ & 0.208 \\
\hline Hypertension & $\begin{array}{l}\text { No } \\
\text { Yes }\end{array}$ & $\begin{array}{l}239 \\
610\end{array}$ & $\begin{array}{l}48 \\
159\end{array}$ & $\begin{array}{l}33.3(31.6-35.1) \\
31.4(30.2-32.5)\end{array}$ & 0.083 \\
\hline COPD & $\begin{array}{l}\text { No } \\
\text { Yes }\end{array}$ & $\begin{array}{l}752 \\
97\end{array}$ & $\begin{array}{l}174 \\
33\end{array}$ & $\begin{array}{l}32.4(31.4-33.4) \\
27.1(24.0-30.3)\end{array}$ & 0.005 \\
\hline Cerebrovascular disease & $\begin{array}{l}\text { No } \\
\text { Yes }\end{array}$ & $\begin{array}{l}632 \\
217\end{array}$ & $\begin{array}{l}155 \\
52\end{array}$ & $\begin{array}{l}31.9(30.8-33.1) \\
30.9(29.2-32.5)\end{array}$ & 0.659 \\
\hline Ischemic heart disease & $\begin{array}{l}\text { No } \\
\text { Yes }\end{array}$ & $\begin{array}{l}661 \\
188\end{array}$ & $\begin{array}{l}157 \\
50\end{array}$ & $\begin{array}{l}32.0(30.1-33.2) \\
31.4(29.4-33.5)\end{array}$ & 0.447 \\
\hline Congestive heart failure & $\begin{array}{l}\text { No } \\
\text { Yes }\end{array}$ & $\begin{array}{l}734 \\
115\end{array}$ & $\begin{array}{l}176 \\
31\end{array}$ & $\begin{array}{l}32.1(31.0-33.1) \\
31.3(28.7-34.0)\end{array}$ & 0.565 \\
\hline PVD & $\begin{array}{l}\text { No } \\
\text { Yes }\end{array}$ & $\begin{array}{l}685 \\
164\end{array}$ & $\begin{array}{l}160 \\
47\end{array}$ & $\begin{array}{l}32.3(31.3-33.4) \\
28.8(26.6-31.1)\end{array}$ & 0.122 \\
\hline Obesity & $\begin{array}{l}\text { No } \\
\text { Yes }\end{array}$ & $\begin{array}{l}782 \\
67\end{array}$ & $\begin{array}{l}196 \\
11\end{array}$ & $\begin{array}{l}31.7(30.7-32.7) \\
32.1(29.4-34.8)\end{array}$ & 0.152 \\
\hline Hyperlipidemia & $\begin{array}{l}\text { No } \\
\text { Yes }\end{array}$ & $\begin{array}{l}501 \\
348\end{array}$ & $\begin{array}{l}113 \\
94\end{array}$ & $\begin{array}{l}32.4(31.1-33.7) \\
31.2(29.7-32.8)\end{array}$ & 0.100 \\
\hline Malignancy & $\begin{array}{l}\text { No } \\
\text { Yes }\end{array}$ & $\begin{array}{l}735 \\
114\end{array}$ & $\begin{array}{l}180 \\
27\end{array}$ & $\begin{array}{l}31.8(30.7-32.9) \\
31.3(29.1-33.5)\end{array}$ & 0.813 \\
\hline Psychiatric disorder & $\begin{array}{l}\text { No } \\
\text { Yes }\end{array}$ & $\begin{array}{l}786 \\
63\end{array}$ & $\begin{array}{l}189 \\
18\end{array}$ & $\begin{array}{l}32.0(31.0-33.0) \\
28.9(25.7-32.1)\end{array}$ & 0.315 \\
\hline Parkinson & $\begin{array}{l}\text { No } \\
\text { Yes }\end{array}$ & $\begin{array}{l}759 \\
90\end{array}$ & $\begin{array}{l}181 \\
26\end{array}$ & $\begin{array}{l}32.1(31.1-33.1) \\
28.7(25.6-31.7)\end{array}$ & 0.332 \\
\hline Atrial fibrillation & $\begin{array}{l}\text { No } \\
\text { Yes }\end{array}$ & $\begin{array}{l}666 \\
183\end{array}$ & $\begin{array}{l}156 \\
51\end{array}$ & $\begin{array}{l}32.3(31.2-33.4) \\
30.7(28.5-32.9)\end{array}$ & 0.274 \\
\hline
\end{tabular}


Table 2 (continued)

\begin{tabular}{|c|c|c|c|c|c|}
\hline Variable & Values & Cases, $N$ & $\begin{array}{l}\text { Events, } \\
N\end{array}$ & $\begin{array}{l}\text { Mean survival days } \\
(95 \% \mathrm{Cl})\end{array}$ & $\begin{array}{l}p \text { value } \\
\text { (log-rank) }\end{array}$ \\
\hline \multicolumn{6}{|l|}{ Medications } \\
\hline \multirow[t]{2}{*}{ Vitamin D } & No & 641 & 168 & $31.3(30.1-32.4)$ & \multirow{2}{*}{0.025} \\
\hline & Yes & 208 & 39 & $33.8(32.1-35.6)$ & \\
\hline \multirow[t]{2}{*}{ Benzodiazepines } & No & 434 & 100 & $32.5(31.2-33.8)$ & \multirow{2}{*}{0.263} \\
\hline & Yes & 415 & 107 & $31.3(29.9-32.8)$ & \\
\hline \multirow[t]{2}{*}{ Beta-blockers } & No & 540 & 126 & $32.2(31.0-33.4)$ & \multirow{2}{*}{0.333} \\
\hline & Yes & 309 & 81 & $31.4(29.7-33.1)$ & \\
\hline \multirow[t]{3}{*}{ Narcotics } & No & 787 & 191 & $31.9(30.9-32.9)$ & \multirow{3}{*}{0.717} \\
\hline & Yes & 62 & 16 & $30.4(27.2-33.6)$ & \\
\hline & Yes & 216 & 59 & $31.1(29.1-33.1)$ & \\
\hline \multirow[t]{2}{*}{ Aspirin } & No & 690 & 178 & $31.5(30.4-32.6)$ & \multirow{2}{*}{0.045} \\
\hline & Yes & 159 & 29 & $33.8(31.8-35.9)$ & \\
\hline \multirow[t]{2}{*}{ Prophylactic anticoagulants } & No & 784 & 197 & $31.6(30.6-32.6)$ & \multirow{2}{*}{0.060} \\
\hline & Yes & 65 & 10 & $33.6(31.1-36.1)$ & \\
\hline
\end{tabular}

$\mathrm{Cl}$, confidence interval; COPD, chronic obstructive pulmonary disease; PVD, peripheral vascular disease.

Table 3. Multivariate Cox regression analysis of risk factors for severe symptomatic disease

\begin{tabular}{lll}
\hline Variable & Hazard ratio $(95 \% \mathrm{Cl})$ & $p$ value \\
\hline Age $^{*}$ & $1.23(1.10-1.40)$ & 0.001 \\
Gender, male & $1.41(1.10-1.88)$ & 0.02 \\
Charlson Comorbidity Index** & $1.00(0.94-1.11)$ & 0.602 \\
Hypertension & $1.23(0.88-1.72)$ & 0.224 \\
COPD & $1.81(1.23-2.67)$ & 0.003 \\
PVD & $1.30(0.91-1.86)$ & 0.154 \\
Obesity & $0.60(0.32-1.10)$ & 0.099 \\
Hyperlipidemia & $1.32(1.00-1.75)$ & 0.051 \\
Vitamin D & $0.70(0.49-1.00)$ & 0.051 \\
Anticonvulsants & $0.61(0.31-1.20)$ & 0.155 \\
Aspirin & $0.74(0.49-1.10)$ & 0.133 \\
Prophylactic anticoagulants & $0.59(0.31-1.11)$ & 0.103 \\
\hline
\end{tabular}

$N=849,-2$ log likelihood $=2,610.899, \mathrm{x}^{2}=47.189, \mathrm{df}=12, p<$ 0.001 . $\mathrm{Cl}$, confidence interval; COPD, chronic obstructive pulmonary disease; PVD, peripheral vascular disease. ${ }^{*}$ Age - per 1-year increment. ${ }^{* *}$ Charlson Comorbidity Index - per one-grade increment.

aspirin and vitamin $\mathrm{D}$ seemed to have a significant protective effect. The effect of treatment with other medications, such as antihypertensive drugs, statins, or antidiabetes drugs including insulin, did not reach statistical significance (Table 2). Mean survival was significantly higher in the earlier admission period (first 4 months).
Of the 159 residents receiving aspirin, 62 (39\%) were also treated with vitamin D compared to $146 / 690(21.2 \%)$ treated with vitamin $\mathrm{D}$ in the rest of the cohort $(p<$ 0.001). In a multivariate analysis (Table 3 ), older age, gender, and COPD remained significant risk factors for reaching the composite outcome (online suppl. Fig. 1; see www.karger.com/doi/10.1159/000521412 for all online suppl. material). There was a trend toward a protective effect for obesity and vitamin D treatment.

\section{Discussion}

In this retrospective cohort study, we describe the outcomes of pre- and asymptomatic SARS-CoV-2-positive, severely frail older adults, admitted for isolation and treatment in designated units at skilled nursing homes. A total of 207 residents $(24.5 \%)$ reached the composite outcome of death or hospitalization by day 40 , and $35 \%$ reached it in a survival analysis. These outcomes are in concordance with previous published data [14-16]. Previous studies including ours show a wide range of presymptomatic disease in nursing homes (10\%-89\%) [14, $15]$. These are probably a result of methodological differences.

Age was a significant risk factor both in the univariate and multivariate analyses. Male sex and COPD were also 
significant risk factors in the multivariate analysis, in alignment with previous published data [17-20]. Association with other comorbidities such as hypertension, diabetes, cardiovascular disease, and kidney disease has not reached statistical significance. This probably is a result of the high comorbidity burden demonstrated by the Charlson Comorbidity Index. The high prevalence of cognitive impairment and very low performance status of the study population probably prevented these factors from reaching statistical significance, contrary to prior publications [20]. The effect of treatment with antihypertensive drugs, statins, or antidiabetes drugs including insulin did not reach statistical significance, probably due to similar reasons.

An interesting finding was the association of aspirin and vitamin $\mathrm{D}$ with a longer time to the primary outcome. We hypothesize that people given vitamin $\mathrm{D}$ and aspirin are "well-managed patients" (the "healthy user" or "wellmanaged" bias). This hypothesis is supported by the high overlap of people treated with aspirin and people treated with vitamin $\mathrm{D}$. We did not find a pathophysiological explanation for such an association. The high prevalence of treatment with both aspirin and vitamin D may suggest that this cohort included many well-managed patients, with high compliance to both primary and secondary prevention. The association of the primary outcome and aspirin treatment was no longer significant in the multivariate analysis. Low vitamin $\mathrm{D}$ levels were previously described as a risk factor for COVID-19 infection; however, studies regarding vitamin D's treatment efficacy showed mixed results, and controversy regarding this treatment for COVID-19 patients remains [21-26].

Obesity emerged as a possible protective factor in the multivariate analysis. Weight loss has been described as a dominant symptom of COVID-19 infection in the old and frail, thus perhaps suggesting a possible protective effect of overweight in older adults $[27,28]$. Overweight and obesity have previously been described as having a protective effect in older age [29]. In our study, we believe these results stem from obesity being an indication of less sarcopenic or frail residents, thus less prone to adverse events of COVID-19.

The higher survival rate in the later months compared to the earlier ones might be a result of the experience gained by the staff in treating COVID-19 patients and might serve as a possible testament to the advantages of this treatment method. It is possible that better treatment protocols introduced as the knowledge of the disease grew and residents' variability also contributed to this outcome.

Frail Older Adults with Asymptomatic COVID-19
This study's population comprised pre- and asymptomatic older adults, found positive in COVID-19 screening tests. The rate of true asymptomatic infection (in comparison with presymptomatic one) is known to be much lower in older adults [30,31]. It is also established that most people who become infected with SARSCoV-2 will not remain asymptomatic throughout the course of the infection [32]. Therefore, the fact that our cohort of patients started as pre- or asymptomatic probably had either low or no impact on the final severity of their disease.

We implemented large-scale, frequent, COVID-19 screening tests of the nursing homes population; positive residents were isolated in designated COVID-19 units inside skilled nursing homes (more detailed description of this care system can be found in online suppl. material). Besides allowing for better source control in the nursing homes (with the price of transferring residents to a different department or facility), this method has several possible benefits. Many concerns have been raised regarding the effect of social isolation on older adults' mental health $[33,34]$. At the designated units, residents benefited from a daily routine despite quarantining. Tenants could enjoy the company of others; they were not sequestered alone in their rooms. Residents were taken out of beds to a shared common room daily, ate at a dining table with other tenants, and had social interactions and activities. Staff members (with PPE) were always present inside the units, addressing all needs. By preventing solitary isolation and giving immediate care by a more available and experienced staff in treatment of older COVID-19 patients and residents, we hoped to achieve better infection control and overall outcomes for residents. In this study population, which had a very low performance status and high prevalence of cognitive impairment, such advantages might manifest as lower delirium rates, lower use of psychoactive medications, etc. However, since there was no control group, proving this hypothesis is beyond the scope of this study. Nevertheless, it is worth noting that even in this severely frail population, most residents were discharged without reaching the primary outcome, with final outcomes matching previous publication $[35,36]$.

Our study has several limitations, mainly due to its retrospective nature. We had limited follow-up periods on residents who were discharged prior to the 40 -day followup. These residents were considered COVID-19 free at discharge in concordance with guidelines at the time. It is highly unlikely they developed COVID-19-related symptoms after discharge. The same argument applies to those 
excluded after an over 40-day stay. Due to the high prevalence of screening tests applied in nursing homes in Israel, we stipulated that upon detection, symptomatic patients are relatively rare compared to presymptomatic ones, and therefore outcomes would not differ significantly from those described at nursing homes in prior publications. Furthermore, our hypothesis was that this severely frail population would suffer worse outcomes. Important outcomes to the older adult population, such as weight loss, delirium, depression, and functional decline, were beyond the scope of our study and so were long COVID-19 symptoms.

\section{Conclusion}

In this large cohort, we present the outcomes of treatment at designated COVID-19 units, along with possible advantages of this treatment method. We believe this unique management method optimizes caring for SARSCoV-2-positive, pre- and asymptomatic frail older adults. Our results show that most residents did not develop severe infection, and that age stays a predominant risk factor, even in the frailest older adults. Further research is needed to assess the impact of vitamin $\mathrm{D}$ and nutritional status on COVID-19 outcomes in this population. More importantly, more studies are needed to assess potential advantages of the designated units regarding major geriatric outcomes such as delirium, weight loss, depression, functional decline, and cognitive impairment. We hope our study adds another brick to the incomplete road of better care for the older nursing home residents, in this and future crises.

\section{Statement of Ethics}

This study was approved by the Local Institutional Review Board of Assaf Harofe Hospital and conforms to the principles outlined in the Declaration of Helsinki (IRB 0055-20-ASF). Due to the study's retrospective nature, informed consent was waived by the Local Institutional Review Board of Assaf Harofe Hospital Ethics Committee.

\section{Conflict of Interest Statement}

The authors have no conflicts, financial or others, to disclose.

\section{Funding Sources}

No funding was used in this study.

\section{Author Contributions}

Y.L. initiated the study, contributed to data collection, analysis, and interpretation, and drafted the manuscript. A.T. contributed to data analysis and interpretation. L.C. provided critical revisions. N.K. contributed to data acquisition. N.T. contributed to data acquisition. T.S. contributed to data acquisition. A.H. provided critical revisions. A.W. provided critical revisions. Y.B. provided critical revisions. Y.L.W. contributed to data analysis and interpretation and drafted the manuscript.

\section{Data Availability Statement}

All data generated or analyzed during this study are included in this article and its online supplementary material. Further enquiries can be directed to the corresponding author.

\section{References}

1 Hu B, Guo H, Zhou P, Shi ZL. Characteristics of SARS-CoV-2 and COVID-19. Nat Rev Microbiol. 2020;19:141-54.

2 Tehrani S, Killander A, Åstrand P, Jakobsson J, Gille-Johnson P. Risk factors for death in adult COVID-19 patients: frailty predicts fatal outcome in older patients. Int J Infect Dis. 2021;102:415-21.

3 Hewitt J, Carter B, Vilches-Moraga A, Quinn TJ, Braude P, Verduri A, et al. The effect of frailty on survival in patients with COVID-19 (COPE): a multicentre, European, observational cohort study. Lancet Public Health. 2020;5:e444-51.

4 Grabowski DC, Mor V. Nursing home care in crisis in the wake of COVID-19. JAMA. 2020; 324:23-4.
5 Ouslander JG, Grabowski DC. COVID-19 in nursing homes: calming the perfect storm. J Am Geriatr Soc. 2020;68:2153-62.

6 D’Adamo H, Yoshikawa T, Ouslander JG. Coronavirus disease 2019 in geriatrics and long-term care: the ABCDs of COVID-19. J Am Geriatr Soc. 2020;68:912-7.

7 Israel Ministry of Health [cited 2021 Mar 5]. Available from: https://govextra.gov.il/ministry-of-health/care-covid19/instructions/.

8 Zhou F, Yu T, Du R, Fan G, Liu Y, Liu Z, et al. Clinical course and risk factors for mortality of adult inpatients with COVID-19 in Wuhan, China: a retrospective cohort study. Lancet. 2020;395:1054-62.
9 Wu Z, McGoogan JM. Characteristics of and important lessons from the coronavirus disease 2019 (COVID-19) outbreak in China: summary of a report of 72314 cases from the Chinese Center for disease control and prevention. JAMA. 2020;323:1239-42.

10 Rockwood K, Song X, MacKnight C, Bergman H, Hogan DB, McDowell I, et al. A global clinical measure of fitness and frailty in elderly people. Can Med Assoc J. 2005;173:48995.

11 RECOVERY Collaborative Group; Horby P, Lim WS, Emberson JR, Mafham M, Bell JL, et al. Dexamethasone in hospitalized patients with Covid-19. N Engl J Med. 2021;384:693704 
12 Charlson ME, Pompei P, Ales KL, MacKenzie CR. A new method of classifying prognostic comorbidity in longitudinal studies: development and validation. J Chronic Dis. 1987;40: 373-83.

13 Katz S, Ford AB, Moskowitz RW, Jackson BA, Jaffe MW. Studies of illness in the aged. the index of ADL: a standardized measure of biological and psychosocial function. JAMA. 1963;185:914-9.

14 Arons MM, Hatfield KM, Reddy SC, Kimball A, James A, Jacobs JR, et al. Presymptomatic SARS-CoV-2 infections and transmission in a skilled nursing facility. N Engl J Med. 2020; 382:2081-90.

15 Graham NSN, Junghans C, Downes R, Sendall C, Lai H, McKirdy A, et al. SARS-CoV-2 infection, clinical features and outcome of COVID-19 in United Kingdom nursing homes. J Infect. 2020;81:411-9.

16 Kennelly SP, Dyer AH, Noonan C, Martin R, Kennelly SM, Martin A, et al. Asymptomatic carriage rates and case fatality of SARSCoV-2 infection in residents and staff in Irish nursing homes. Age Ageing. 2021;50:49-54.

17 Shahid Z, Kalayanamitra R, McClafferty B, Kepko D, Ramgobin D, Patel R, et al. COVID-19 and older adults: what we know. J Am Geriatr Soc. 2020;68:926-9.

18 Dorjee K, Kim H, Bonomo E, Dolma R. Prevalence and predictors of death and severe disease in patients hospitalized due to COVID-19: a comprehensive systematic review and meta-analysis of 77 studies and 38,000 patients. PLoS One. 2020;15:e0243191.

19 Zheng Z, Peng F, Xu B, Zhao J, Liu H, Peng J, et al. Risk factors of critical \& mortal COVID-19 cases: a systematic literature review and meta-analysis. J Infect. 2020;81:e16-25.

20 Panagiotou OA, Kosar CM, White EM, Bantis LE, Yang X, Santostefano CM, et al. Risk factors associated with all-cause 30 -day mortality in nursing home residents with COVID-19. JAMA Intern Med. 2021;181:439-48.
21 Hastie CE, Mackay DF, Ho F, Celis-Morales CA, Katikireddi SV, Niedzwiedz CL, et al. Vitamin D concentrations and COVID-19 infection in UK Biobank. Diabetes Metab Syndr. 2020;14:561-5.

22 Meltzer DO, Best TJ, Zhang H, Vokes T, Aro$\mathrm{ra} \mathrm{V}$, Solway J. Association of vitamin D status and other clinical characteristics with $\mathrm{CO}$ VID-19 test results. JAMA Netw Open. 2020; 3:e2019722.

23 Ma H, Zhou T, Heianza Y, Qi L. Habitual use of vitamin $\mathrm{D}$ supplements and risk of coronavirus disease 2019 (COVID-19) infection: a prospective study in UK Biobank. Am J Clin Nutr. 2021;113:1275-81.

24 Annweiler G, Corvaisier M, Gautier J, Dubée V, Legrand E, Sacco G, et al. Vitamin D supplementation associated to better survival in hospitalized frail elderly COVID-19 patients: the GERIA-COVID Quasi-Experimental Study. Nutrients. 2020;12:3377.

25 Cereda E, Bogliolo L, Lobascio F, Barichella M, Zecchinelli AL, Pezzoli G, et al. Vitamin D supplementation and outcomes in coronavirus disease 2019 (COVID-19) patients from the outbreak area of Lombardy, Italy. Nutrition.. 2021;82:111055.

26 Rubin R. Sorting out whether vitamin D deficiency raises COVID-19 risk. JAMA. 2021; 325(4):329-30.

27 Anker MS, Landmesser U, von Haehling S, Butler J, Coats AJS, Anker SD. Weight loss, malnutrition, and cachexia in COVID-19: facts and numbers. J Cachexia Sarcopenia Muscle. 2021;12(1):9-13.

28 Di Filippo L, De Lorenzo R, D’Amico M, Sofia V, Roveri L, Mele R, et al. COVID-19 is associated with clinically significant weight loss and risk of malnutrition, independent of hospitalisation: a post-hoc analysis of a prospective cohort study. Clin Nutr. 2021;40(4):2420-6.
29 Oreopoulos A, Kalantar-Zadeh K, Sharma AM, Fonarow GC. The obesity paradox in the elderly: potential mechanisms and clinical implications. Clin Geriatr Med. 2009;25:643viii.

30 Sah P, Fitzpatrick MC, Zimmer CF, Abdollahi E, Juden-Kelly L, Moghadas SM, et al. Asymptomatic SARS-CoV-2 infection: a systematic review and meta-analysis. Proc Natl Acad Sci USA. 2021;118:e2109229118.

31 Sakurai A, Sasaki T, Kato S, Hayashi M, Tsuzuki SI, Ishihara T, et al. Natural history of asymptomatic SARS-CoV-2 infection. N Engl J Med. 2020;383:885-6.

32 Buitrago-Garcia D, Egli-Gany D, Counotte MJ, Hossmann S, Imeri H, Ipekci AM, et al. Occurrence and transmission potential of asymptomatic and presymptomatic SARSCoV-2 infections: a living systematic review and meta-analysis. PLoS Med. 2020;17: e1003346.

33 Blazer D. Social isolation and loneliness in older adults: a mental health/public health challenge. JAMA Psychiatry. 2020;77:990-1.

34 Manca R, De Marco M, Venneri A. The impact of COVID-19 infection and enforced prolonged social isolation on neuropsychiatric symptoms in older adults with and without dementia: a review. Front Psychiatry. 2020; 11:585540

35 Shi SM, Bakaev I, Chen H, Travison TG, Berry SD. Risk factors, presentation, and course of coronavirus disease 2019 in a large, academic long-term care facility. J Am Med Dir Assoc. 2020;21:1378-83.

36 Hashan MR, Smoll N, King C, OckendenMuldoon H, Walker J, Wattiaux A, et al. Epidemiology and clinical features of COVID-19 outbreaks in aged care facilities: a systematic review and meta-analysis. EClinicalMedicine. 2021;33:100771. 